\title{
"La misericordia y la fidelidad se encuentran" (Salmo 84) La lucha por la justicia y la misión, se besan Conclusión de las jornadas del V Centenario de San Francisco Javier
}

\author{
José Ignacio González Faus \\ San Cugat del Vallés, Barcelona \\ Centro de Reflexión Teológica, San Salvador
}

Del 13 al 16 de noviembre se celebraron en Javier (Navarra, España), unas jornadas para clausurar el V Centenario de San Francisco Javier. Antes de las jornadas, se trabajó con unas largas encuestas a gente de base, de África (Camerún, Congo, Tanzania), Asia (Filipinas, India, Corea), América Latina (Guatemala, Perú, Brasil, México) y primer mundo (Canadá, España, Italia). Ya en Javier, dos representantes de cada una de las experiencias encuestadas, que habían sido invitados a las jornadas, expusieron lo fundamental de la experiencia con ayuda de medios audiovisuales y su propia palabra. Tras la exposición de cada continente o región, dos teólogos o teólogas presentaron sus reflexiones. Fueron en total tres teólogos y tres teólogas. Al final, ofrecí mi propia reflexión, que quería ser una especie de balance-conclusión de todo lo que se dijo en las jornadas. Es lo que escribo a continuación.

\section{Introducción}

En mi primera lectura de los trabajos de campo me sorprendió la coincidencia de los testimonios en muchas intuiciones, que ahora enumeraré. Y he visto al 
leerlas que, pese a la diversidad de culturas, lenguas, sistemas sociales, costumbres, vestidos..., el dolor y las víctimas son iguales en todas partes, y pueden ser el camino para el encuentro y la armonía de las diversidades, tanto en lo cultural como en lo religioso. Esa lectura me evocó el título de un libro que hace unos años publicamos en Cristianismo y justicia: Universalidad de Cristo. Universalidad del pobre. Ese título hace de hilo conductor de muchas cosas que intentaré pensar y decir aquí.

Esas intuiciones que me han parecido tan coincidentes podría ser las siguientes:

1. La intuición cristológica: la presencia anonadada de Dios en el mundo "como un hombre cualquiera"... "hecho víctima" o siervo (Fil 2, 7ss).

2. La intuición antropológica: la suprema dignidad del ser humano como imagen de Dios, por destrozada que aparezca esa imagen, tanto por la inhumanidad de unos como en la infrahumanidad de otros.

3. La intuición pneumatológica: necesidad (y experiencia) de la presencia y la fuerza del Espíritu para aceptar y vivir las tesis anteriores. "Es Dios el que ha echado a andar esto", dijo uno de los aquí presentes, al exponer el trabajo en Loyolaetxea.

4. La intuición eclesiológica: el dolor por la lejanía de la autoridad eclesiástica, respecto a las víctimas de la historia y de aquellos que trabajan en su favor.

5. Entre los testimonios no hay igual coincidencia, sino mayor diversidad respecto a la conducta del primer mundo. Según continentes y personas, se pasa de la denuncia a la comprensión y hasta la gratitud.

Después de oír las diversas reflexiones, intentaré ahora combinar esas intuiciones, en un engranaje de siete tesis. Creo que la primera intuición se reflejará más en las tesis dos, tres, y cinco. La segunda, en las tesis uno y cuatro. La tesis seis recogerá la cuarta, y la séptima, la quinta de las intuiciones que acabo de enumerar.

Vamos pues allá.

Primera tesis. El cristiano ha de actuar en la misión y en la lucha por la justicia como un perdonado y no como un salvador.

Denise Acckermann decía que leer los testimonios resultaba para nosotros humillante (humbling). Efectivamente. Para empezar, los pobres nos colocan en nuestro sitio. Y, por lo general, lo hacen acogiéndonos y sin agredirnos. Pero por eso, añadía J. Vitoria, también "sanan".

Hay aquí algo que me parece muy fundamental. Los apóstoles se pusieron a predicar desde una experiencia de perdón: la manifestación del resucitado llevaba anexa una experiencia de que Dios les había perdonado a ellos, a sus verdugos y a toda la humanidad. De esta humanidad nuestra dice la Biblia $-\mathrm{y}$ 
nos lo recordó la delegación brasileña—, que Dios vio lo que había creado y era muy bueno. Pero añade poco después, que Dios "se arrepintió de haber creado al hombre". Resucitando a Jesús, Dios revela que ya no le pesa haber creado al género humano. Y éste es uno de los factores que pone en marcha la misión.

En otro sentido, la primera presentación pública de Jesús nos lo presenta ante el Bautista, alineado junto a los pecadores como uno más, compartiendo esa culpa de su pueblo, que Juan había denunciado duramente.

En este contexto, nuestra misión, nuestra salida al anuncio de la fe y a la lucha por la justicia y la dignidad del hombre, sólo puede nacer de una experiencia similar de perdonados. El encuentro con las víctimas ha sido para muchos una concreción de esa experiencia que, para no aburrir con muchas ideas, voy a intentar narrar, parodiando la escena evangélica de la mujer adúltera.

Ese sector de la humanidad que creemos que ha adulterado totalmente la finalidad de la creación, sembrando injusticia y odio, es llevado ante Jesús. Le preguntan qué hay que hacer con esa humanidad y responde como en el cuarto evangelio: "quien de ustedes esté sin pecado, que le tire la primera piedra". Al oír esto, "todos se fueron marchando, comenzando por los más jóvenes". Pero entonces, Jesús los llamó gritándoles: "no se marchen que no voy a condenales". Y varios de ellos fueron volviendo, poco a poco, delante de Jesús, y le dijeron: "Señor, si tú no nos condenas tampoco nosotros la condenamos a ella". Entonces, Jesús se volvió a la acusada y le dijo: "¿nadie te ha condenado? Pues tampoco te condeno yo. Vete y no vuelvas a pecar".

¿Por qué es tan importante esa actitud de perdonados? Porque sólo desde ella es posible cumplir la primera bienaventuranza de las que propuso Denise: "dichosos los que valoran la dignidad de los demás, porque no estigmatizarán". Efectivamente, estigmatizar al pobre, al marginado, es la tendencia de todo ser humano, creyente o no creyente: en tiempo de Jesús, los leprosos eran impuros; en tiempo de George Bush, hay otros impuros, que son "eje del mal" - iel cual sirve para que nosotros nos sintamos eje del bien! En la religión del mercado, configuradora de nuestro sistema económico, el pobre lo es por su culpa: porque no supo aceptar las oportunidades que ofrece el mercado a todas las personas racionales.

Como dijo ayer Teresa Okure, todos somos receptores del perdón, en primer lugar. Yo quisiera hablar hoy aquí como receptor del perdón ante todo. Para que todos luego vayamos como perdonados, a luchar sin estigmatizar a nadie.

Segunda tesis. A Dios hay que buscarle donde Él dice que está. No donde a nosotros nos gustaría encontrarlo.

La lectura y la escucha de todas las intervenciones que me han precedido, me ha ido confirmando una frase de Antonio González: "Dios se reveló no como buena noticia para los intelectuales, sino como buena noticia para los ricos". Efecti- 
vamente, en el mundo rico se oye decir hoy con frecuencia que Dios está ausente; que no se manifiesta. La cultura del primer mundo ha inoculado la idea de que la tecnología sustituye a Dios, y resuelve los problemas, por los que buscaban los hombres a Dios, mostrando su no existencia. Acomodados en alguna de sus espléndidas mansiones, con su whisky y su piscina, los ciudadanos del mundo rico esperan que Dios venga a dejarse ver. Algunos incluso esperan que, si viene, habrá de ser para defender su sacrosanto derecho de propiedad. Otros, a lo más, quizá busquen un poco de descanso en una religiosidad vaga, en ese atractivo que en occidente tiene un oriente falseado: en eso que nosotros llamamos "yoga para ejecutivos".

Esta pintura contrasta con un detalle muy repetido en la Biblia: Dios no se revela por la línea de la vista, sino por la del oído. No dejándose ver, sino llamando. La vista nos da la sensación de que poseemos al objeto, lo dominamos y podemos valorarlo o manejarlo. Pero el Dios bíblico no entrega Su Nombre, no se deja ver. A lo más, percibimos su espalda al pasar, en un soplo suave - como dice el profeta Elías. Nos llega su voz. Y es una voz que llama: "sal" (de tu entorno y de tu parentela); "ve" (a liberar a mi pueblo)... No da información sobre Él, sino que pide obediencia a su llamada.

Esto resulta inaceptable, no sólo para nuestra comodidad establecida, sino para nuestra razón occidental (griega), para la cual conocimiento es lo mismo que posesión y poder, y toda experiencia de gratuidad parece un atentado a nuestra identidad orgullosa: "hacer, hacer, hacer", escuchábamos el lunes, en esta misma sala. Quizá por eso, en esta España (antaño oficialmente católica y hoy tierra de misión), se produce un impacto y una sensación de novedad y de sospecha, cuando algunas figuras de las iglesias latinoamericanas (Jon Sobrino, Óscar Romero, Ignacio Ellacuría, Gustavo Gutiérrez...) han pasado por aquí. Es una sensación donde - amén de la clásica curiosidad - se mezclan admiración, sospecha, sensación de novedad y un poco de esperanza. Puedo ejemplificar esa sensación en dos respuestas de gente no cristiana.

Una muchacha buena y cariñosa con la que hablo a veces, con ese analfabetismo religioso típico de su generación, me oyó una vez, en una conversación, esta frase de Teresa de Calcuta: "que todo el que hoy trate conmigo se vuelva más contento". Inmediatamente reaccionó con espontaneidad: "esa sí que era una mujer generosa". Pero a continuación, ella misma se corrigió: "pero bueno, también demasiado: yo creo que se pasó, porque una también tiene derecho a ser feliz"... Admiración, sospecha y un poquito de esperanza, acabó de decir.

1. Aunque esto no lo dije en la charla de Javier, debo añadir aquí que prefiero la reacción sincera y noblota de esta muchacha a todas las manipulaciones que de la madre Teresa hizo la derecha económica, agradeciéndole que les barriera las calles de cadáveres, sin exigirles a ellos que no las ensuciasen. 
La otra anécdota tuvo lugar en Barcelona, durante la presentación del libro de PPC, Cincuenta cartas a Dios. De los tres que había en la mesa (además del director de la editorial), uno era José María Mendiluce, autor de la carta quizá más dura de todo el libro, que termina diciéndole a Dios: "prefiero que no existas porque, de lo contrario, no tendría más remedio que odiarte". El autor nos dijo que había escrito aquella página trasladando cadáveres (no ya cadáveres: huesos) de musulmanes muertos, víctimas de sus vecinos serbios cristianos y de su nacionalismo incontrolado. Pero a continuación añadió, más o menos, el testimonio que sigue: "de todos modos, quiero deciros que no me considero ateo sino agnóstico. Porque, a la vez que hunde y me rebela tanto mal como veo, he de reconocer que, en casi todos los sitios más duros por los que he pasado he visto testimonios y actuaciones tan impresionantes de cristianos y de misioneros que me obligan a suspender el juicio...”.

Creo que ambas anécdotas reflejan mejor que mis elucubraciones lo que he querido decir. Este embotamiento del mundo rico contrasta con el anhelo de Dios (longing for God) de que habló también Denise. Y esto nos lleva a la tesis siguiente.

Tercera tesis. En Jesucristo, Dios ha revelado que debemos buscarle (y anunciarle) a través de aquello que Jesús llamaba Reino de Dios, cuyos propietarios son los pobres. Y, por tanto, en las víctimas de esta sociedad estructurada como el "Antirreino". Lo reveló no sólo con sus gestos y palabras, sino haciéndose Él víctima de los hombres.

Todos los testimonios (y luego los teólogos) han hablado de mil maneras acerca del atractivo y de la seducción de la figura de Jesús — "frente al poco atractivo de la Iglesia", añadía Amaladoss-, y de esa figura que es a la vez subversiva y subyugante. "Así de humano sólo puede serlo el mismo Dios", escribió hace años Leonardo Boff. La seducción de Jesús emparenta entonces con el anhelo de Dios. De ese Dios da testimonio el Nuevo Testamento, ya en uno de sus primeros escritos y en uno de los más tardíos.

En el himno de la carta a los filipenses, leemos de Jesús que "se despojó de su condición divina presentándose como un hombre cualquiera y asumiendo figura de siervo". Es el mismo Jesús del que el cuarto evangelio nos dice: "quien me ve a mí ve al Padre". Ese mismo evangelio de Juan anuncia en su prólogo, que la Palabra Eterna de Dios se hizo pobreza humana, "carne", y que precisamente ahí es donde hemos visto Su Gloria. Así será la revelación de Dios a nosotros, mientras este mundo sea como es.

Y esa revelación da una coloración especial al anhelo de Dios antes citado, que convierte la búsqueda de Dios en búsqueda de Su Reino, y que nos lleva a una mística que ya no es "de ojos cerrados", sino "de ojos abiertos". Quisiera visibilizar esa mística retomando el consejo que dio una vez Gustavo Gutiérrez: 
hay que hacer una lectura política de san Juan de la Cruz — con la clásica aclaración de que el adjetivo subrayado no se refiera a política de partidos, sino que trata de incluir a toda la comunidad humana.

Por ejemplo, es bien conocida aquella estrofa del místico sobre "la llaga", —el anhelo con el lenguaje de estos días que he recogido aquí:

¿Por qué, pues has llagado

aqueste corazón, no le sanaste?

Y, pues me le has robado,

¿por qué así le dejaste

y no tomas el robo que robaste?

Leamos esa estrofa referida a todo el género humano, y recémosla en nombre de toda la humanidad tan doliente. Podría sonar más o menos así: “¿por qué, pues, has llagado a nuestra humanidad, no la sanaste? Y, pues nos has salvado ¿por qué así nos dejaste y no tomas el mundo que salvaste?

Creo que es una excelente oración, que no hace más que parafrasear el Padrenuestro: Abbá, glorifica Tu Nombre; venga Tu Reino. Y puede arrancar ya desde el inicio del Cántico: ¿A dónde te escondiste, Amado, y nos dejaste con gemido? Como el ciervo huíste habiéndonos herido. Fuimos tras Ti corriendo y eras ido...

A eso llamé lectura política: a una mística que no es vivida en clave personal o individual (el alma y Dios), sino colectiva. Semejante mística tiene también sus caminos de "noche oscura", de la que valen los mismos consejos que daba Juan de Yepes, en el poema del mismo título: salimos, "con ansias en amores inflamados". Pero "estando nuestra casa sosegada" y, a veces, "sin otra luz ni guía sino la que en el corazón ardía"... Hasta llegar a aplicar a toda la humanidad (o a todo un grupo) la estrofa más bella del poema:

$¡ O h$ noche que guiaste!

¡Oh noche amable, más que la alborada!

¡Oh noche que juntaste

Amado con amada, amada en el amado transformada!

Ahora, la unión con la amada es fusión de Dios con toda la humanidad y no sólo con mi alma. ¿No es ésta la meta para la que hemos sido creados todos? Por eso, creo que una mística de esas es la que expresaba (quizá sin saberlo) alguien de la Loyolaetxea, cuando el otro día hablaba de la importancia del compartir vida. No sólo dar, ni sólo transformar (cosa que no sabemos cuándo ni cómo será), igual que otros han hablado de la importancia de la comunidad, en la lucha por la justicia. 
Y podemos acabar esta tesis recordando que toda esta mística, como enseñaba Antonieta Potente, hablando de la experiencia, no es un fenómeno puntual ni rápido, sino algo lento, relacionado con la misteriosa lentitud del tiempo.

Cuarta tesis. El mundo rico debe hacer suya la frase de Nicolás Berdaieff: "el pan para mí es un problema material; el pan para mi prójimo es un problema espiritual".

En un escrito en el que ando ahora metido, he reformulado así la frase de Berdiaeff: el pan para mí es una cuestión pagana; el pan para mi prójimo es una cuestión cristológica. Quizá esto dará más posibilidades de reflexión.

Esta tesis sirve para responder a una acusación no infrecuente en el primer mundo (y hecha a veces desde un misticismo individualista) contra las gentes del tercer mundo. Por ejemplo, "la teología de la liberación es demasiado materialista"; o "los cristianos que buscan el socialismo han hecho una reducción materialista del cristianismo"...

En realidad no se trata de una reducción materialista, sino de una ampliación kat-ólica (es decir, universal en el sentido etimológico del término). No perciben los acusadores que los grandes materialistas son ellos. Después de Freud, todos deberíamos saber ya que no hay nada más materialista que una falsa espiritualidad.

Me permitiré visibilizar lo que digo con otra anécdota, esta vez histórica, ocurrida en una diócesis de México, en un momento en que los campesinos se encontraban ante el siguiente dilema: si plantaban maíz, y no coca como les pedían los narcotraficantes, éstos les quemaban las cosechas. Si plantaban coca, cediendo a chantaje de los narcos, el ejército les quemaba los campos. Muchos curas de la diócesis andaban implicados en la lucha y la protesta de los campesinos. Y el obispo, en una reunión, les dijo: “¡no se metan en política!, ¡no se metan en política!. Ustedes como Jesús, que al paralítico le dijo 'perdonados te son tus pecados'; y lo dejó en la camilla". Este obispo no había percibido que su pretendida espiritualidad de vivir ajeno al conflicto no era más que una defensa materialista de su tranquilidad, ni que algo tan espiritual como el perdón de los pecados tenía para Jesús la consecuencia de decir al paralítico: "levántate, toma tu camilla y anda", como requisito para ser creído.

La tesis prolonga "en el Espíritu" —o penumatológicamente - la misma inversión cristológica, de la tesis anterior: igual que reconocemos y vemos a Dios en la "carne" (en el sentido semita negativo, de pobreza y debilidad), en el anonadamiento de la Palabra, del mismo modo encontramos lo "espiritual" en la necesidad material del otro. Alguien preguntó aquí mismo, el lunes pasado, si había algo en común entre colectivos como la Romero's House, Loyolaetxea y Sant Egidio. Pues bien, creo que lo que hay de común, más allá de otras diferencias, es esa inversión de algo material en espiritual. Hecha esa inversión, todas las demás diversidades pueden subsistir: están ya unidas por el Espíritu. 
Pero esta inversión de la mirada sólo puede ser obra del Espíritu de Dios, del mismo Espíritu que nos hace llamar "Señor" a Jesús y llamar Abbá (Padre-Madre) a Dios. Él es el que nos hace invertir esa relación material-espiritual, y cumple lo que nos dijo desde aquí Mari Jo, del Canadá, si la entendí bien: Dios no está en un lugar fijo, o en otro, sino en el movimiento, en el camino hacia el otro. En la Gracia que es una forma de mirada y relación.

Esa inversión, he creído percibirla estos días muchas veces. Y me evocó unos versos de Pedro Casaldáliga que dicen:

El lucro y el poder de vuestras armas

no pueden alcanzar mayor cotización

que el llanto enfebrecido de un niño de color.

Y para concluir esta tesis quiero recordar, una vez más, que el siglo XX nos dejó una impresionante "nube de testigos" — como dice la carta a los Hebreos-, que vivieron esta verdad. Javier Vitoria ya citó algunos. Y creo que su presencia es un signo de los tiempos, el cual no sabemos leer bien. Testigos de una profunda experiencia espiritual. Testigos que fueron en su mayoría mujeres. Y que casi todos eran conversos - de la increencia a la fe, o de una fe rutinaria a otra viva. Pero que todos vivieron y expresaron lo que una de ellas llamó "la mística de las relaciones humanas"2: nombres como Óscar Romero, Dietrich Bonhoeffer, Dorothy Day, Simone Weil, Madeleine Dêlbrel, Etty Hillesum. Maria Skobtsov... Varios de ellos acabaron además mártires. Por eso, deberíamos concluir con el salmo: "si nos llega su voz, no endurezcamos el corazón...".

Esta última observación nos lleva a la tesis siguiente.

Quinta tesis. Las tesis anteriores pueden (y suelen) llevar al cristiano a la persecución, a menos que sean aceptadas por todos.

Si todo lo antes dicho es, para nosotros, seguimiento de Jesús, llega el momento de aplicar sus palabras: "quien quiera seguirme, niéguese a sí mismo y tome su cruz". Estas palabras no son mera invitación a una ascética individual, sino, sobre todo, a una entrega servicial de la propia vida.

En ella podrá suceder que — como mínimo- perdamos posibilidades de éxito personal, de ascenso o de carrera. Podrá ser también que nos veamos sin trabajo como explicó Diodora, o incluso en la cárcel como le pasó a Pak-Sun-Jee. En casos especiales, incluso podemos llegar a esa otra "nube de testigos" (es decir, mártires), que también caracterizó, como otro signo de los tiempos, al pasado siglo: Óscar Romero, E. Angelelli, I. Ellacuría y sus compañeros, las cuatro religiosas estadounidenses violadas y asesinadas, en El Salvador, innumerables

2. Así se titula el segundo capítulo del libro de Maria Skobtsov El sacramento del hermano. 
delegados de la Palabra anónimos, en América Latina, José María Grant y otros de los Sagrados Corazones, en Guatemala, los maristas de Ruanda... Podrá ser incluso, para más irrisión, que el martirio sea recibido como recibió el cardenal Casariego, de Guatemala, la noticia del de José María Grant: "yo no sé si era comunista; lo que sí puedo decir es que no llevaba sotana".

Nos despreciarán o se reirán de nosotros, si no constituimos un peligro grande. Nos perseguirán, si creen que nos hemos convertido en una amenaza. Me he cansado de decir que lo que menos soportan los opresores no es una rebelión, sino un buen ejemplo.

De ahí la importancia de recuperar el sentido más primigenio de la palabra "mártir" como testimonio del amor - a la manera del mártir Maximiliano Kolbe-, no como asesinado por "odio a la fe". Porque una fe que no esté "informada por la caridad", en expresión de Pablo y del concilio de Trento, no tiene consecuencias y, por eso, no la odia nadie. Por culpa de esa falsa definición, la autoridad de la Iglesia católica está rechazando el regalo de tantos mártires con que Dios la distinguió, en el pasado siglo. Y eso es grave.

Sólo la gracia de Dios puede hacer que, en estas condiciones, no perdamos el sentido del humor y la capacidad para la sonrisa franca. El maestro Eckhart decía que "el Espíritu Santo es la sonrisa de Dios". Y en Perú, oí decir una vez: a pesar del dolor estamos alegres, porque lo contrario de la alegría no es el dolor; lo contrario de la alegría es la tristeza.

Y para anticipar lo que será nuestra última tesis, quiero evocar que esta persecución tiene un fundamento ideológico en lo que se llama ideología del TINA (There is no alternative). El mundo rico tiene tanto interés en que esa falta de alternativa sea verdad que, cuanto hemos dicho en las tesis dos, tres y cuatro le suena como una estupidez, una auténtica locura. Y del loco ya sabemos: mientras parece inofensivo, las gentes se ríen de él; si parece ofensivo, se le encierra.

Sexta tesis. La Iglesia debe ser anuncio y signo visible de todo lo anterior (es decir, sacramento de salvación). Esto la convertiría en "Iglesia de los pobres". Y convertiría su celebración en acción de gracias ("eu-caristía") de los pobres.

En todas las respuestas recogidas había un dolor por la actitud de la autoridad eclesiástica. Leyendo muchos de los testimonios, me acordé de la frase de Isaías: “ipuede una madre olvidarse de sus hijos?”. Pues los responsables de la Iglesia se han olvidado de los pobres...

Algunas de esas que Javier Vitoria gusta llamar "historias intempestivas de solidaridad", han terminado con la misma frase con que concluye el Popol Vuh, el poema maya de la creación: "entonces llegaron ellos" (refiriéndose a los españoles). Y ahí, la narración termina abruptamente. Lo ocurrido, por ejemplo, con 
los diáconos de Chiapas, me parece un pecado mortal, que evoca esa frase dolorida: entonces llegaron "ellos"...

Sin embargo, es bonito constatar que los testimonios respiran eclesialidad. La fe cristiana, precisamente porque es fe en un Dios que es Amor y Comunión, es intrínsecamente eclesial, comunitaria. Esta eclesialidad necesita hoy una reforma cuyo camino marcó Amaladoss: "de la Iglesia al Reino de Dios" — no al revés. Y eso, a mi entender, supone:

* Que merezca llamarse Iglesia de los pobres, como la llamó Juan XXIII. $\mathrm{Al}$ menos porque ellos tienen en la Iglesia ese privilegio hermenéutico y esa autoridad que evocó Javier Vitoria.

* La profunda reforma de la concepción y del ejercicio de la autoridad (en papado, obispos y clero), que la aproxime a la inversión evangélica de la autoridad en servicio.

* La unidad de todos los creyentes en Jesucristo, en una sola Iglesia, quizá muy plural, pero única. La pareja del Agostino de Lima que habló aquí el martes, presbiteriana y cura católico, nos hizo ver que, precisamente, la autoridad y el servicio a los pobres y sufrientes son el verdadero pivote unificador y ecuménico, tanto entre las iglesias cristianas como entre las religiones de la tierra.

A esta triple reforma me gusta añadir otro cambio que parece insignificante, pero no lo es. Me refiero a un cambio de lenguaje, no una simple "mejor traducción". El lenguaje brota, en parte, de una mentalidad y una cosmovisión, pero también contribuye a constituirla. Y el lenguaje actual, no ya de la teología, sino — sobre todo - de la liturgia y la oración, es a veces incapaz de poner en oración a la mayoría de las gentes de hoy. En nuestra Iglesia, la lex orandi no coincide con la lex credendi, el lenguaje de la oración con el lenguaje de la fe. Y esto es preocupante.

La profesión de fe de Nicea, por ejemplo, es hoy casi incomprensible para el cristiano medio. Con dificultad pueden profesarse unas verdades que no se entienden.

Muchas frases de los salmos que aparecen en el oficio divino no puede rezarlas un cristiano: "Mató a Hog rey de los amorreos... porque es eterna su misericordia", "sujetar a los reyes con argollas y a los nobles con esposas de hierro... es un honor para todos sus fieles". O la tranquilidad con que la relación con Dios se concibe como un privilegio material, de modo que "caerán mil a tu izquierda y diez mil a tu derecha pero a ti no te alcanzará". Yo, sinceramente, no puedo rezar eso.

En la plegaria que nos dejó Jesús, seguimos diciendo "santificado sea tu Nombre”, sin que, formulado así, podamos saber lo que pedimos. La gente normal 
entiende que no blasfememos o que pronunciemos muchas alabanzas verbales a Dios, como si Él se agradase de ellas. En la Biblia, la santidad de Dios tiene un reflejo que es "su Gloria". Y el "nombre", para un judío, no es meramente la palabra "Dios", sino la profundidad de su ser. "Que Tu Nombre sea glorificado" equivale a pedir que la cruel realidad de este mundo de muerte e injusticia no mancille o deforme el nombre de Abbá con que Jesús nos enseñó a dirigirnos a Dios. La "santificación" de ese Nombre sólo puede ser la venida de su Reino y el cumplimiento de su Voluntad en esta tierra.

Igual problema de lenguaje encontramos en nuestras celebraciones eucarísticas, las cuales ya no parecen acciones de gracias a Dios, porque no necesitamos ofrecerle sacrificios, ni necesitamos sacerdotes para ello, dado que la vida de Jesús, entregada hasta la muerte por nosotros, ha sido el único sacrificio agradable a Dios y lo ha constituido en único sacerdote. Eso es lo que nosotros celebramos y agradecemos, evocando la cena en que el Señor resumió su vida, y disponiéndonos así para vivir entregando también algo de nuestras vidas. En lugar de eso, da la sensación de que seguimos utilizando el concepto de sacerdocio y de sacrificio que la carta a los Hebreos rechazó como "pura sombra", que "no llega hasta el cielo". El léxico sacrificial o victimalista sugiere, al contrario, que la víctima que ofrecemos justifica nuestra falta de atención a las víctimas, pues a Dios ya lo hemos dejado contento. Permítanme expresar el contraste entre esa impresión - "ya hemos contentado a Dios; ahora vamos a lo nuestro"-, y lo que cantaba la misa nicaragüense, en su canto de comunión:

La comunión no es un rito intrascendente y banal.

Es compromiso y vivencia toma de conciencia de la cristiandad.

Es comulgar con la lucha de la colectividad.

Es decir: "yo soy cristiano y conmigo hermano

Vos podés contar".

Que nuestras misas no suelen ser compromiso, ni vivencia, ni toma de conciencia de lo cristiano, no creo que necesite demasiado comentario, por desgracia.

$\mathrm{Y}$, en fin, no sé si exagero aquí exponiendo una preocupación muy personal, dado que cada vez que intento orar a Dios se me desvanecen las palabras, por inútiles, ante la Grandeza y total Alteridad del interlocutor. Pero por otra parte, una oración de puro silencio ha tenido siempre el peligro de olvidar la venida del Reino y el amor al hermano ${ }^{3}$.

Cerremos esta tesis subrayando que esa eclesialidad de la fe habremos de vivirla "en rebelde fidelidad", utilizando el título de un antiguo libro de P. Casadáliga. La fidelidad no es un matiz añadido, sino que es lo sustantivo. El que sea

3. Así lo reconoció el autor de la célebre Nube del no saber, como comenté en otro lugar. 
rebelde, con una rebeldía evangélica, requerirá entre otras mil ayudas, una buena dosis de sentido del humor, que es una gran fuente de paciencia...

Séptima tesis. En un mundo marcado por la convivencia del trigo y la ciza$\tilde{n} a$, no podemos evangelizar, ni luchar por la justicia, olvidando las realidades de "injusticia estructurada" o de pecado estructural.

Esta observación faltaba en muchas respuestas que, por su bondad, sólo agradecían lo que reciben. Pero tengamos en cuenta que vivimos en un sistema económico profundamente injusto: de enorme eficacia a la hora de producir riqueza; pero que sólo la produce a condición de repartirla inicuamente. Hace menos de tres siglos, la diferencia entre el mundo rico y el pobre era de dos a uno. En la segunda mitad del siglo XX, había pasado a ser de sesenta a uno. Ahora, es de noventa a uno $-\mathrm{y}$ son datos del PNUD. Hay además, en muchas gentes, una especie de negativa visceral a aceptar esta realidad.

Extraña, pues, que casi no haya aparecido estos días el tema de la globalización, y de las luchas contra ella (Seattle, Portoalegre, Génova...). Se globaliza la ambición primermundista y poco más. Yo sueño con una mundialización ideal, hecha con la sonrisa de África, con la acogida de América Latina, la paz y la riqueza interior del Asia, la ambición europea y norteamericana $-\mathrm{y}$ si suena negativa la palabra ambición, hablemos de desacralización, es decir, del mundo puesto en manos del ser humano, pero ; como administrador, no como monarca absoluto! Sin esa forma de mundialización, vamos a llegar a medio mundo con VIH y otro con VIS, Virus de Inmunodeficiencia Solidaria; medio mundo con SIDA y otro medio con SISA, Síndrome de Inmunodeficiencia Solidaria Adquirida. Y al hacer estos juegos de palabras, me ha hecho gracia caer en la cuenta de que en castellano la palabra sisa significa precisamente robo...

No tenemos alternativas globales al sistema. Ni es posible tenerlas de antemano, como creyó Marx. Pero sí tenemos posibles caminos en la dirección contraria, que serán más útiles cuanta más gente se anime a seguirlos. Ahí está el último Nobel de la paz, Mohamed Yunus, de quien se dijo que más bien debieron haberle dado el Nobel de economía...

Para nosotros, teólogos, esto significa que las ciencias sociales son hoy tan necesarias para la teología como lo fue antaño la filosofía, y sin abandonar a ésta, porque brota muy hondamente de la necesidad humana de preguntar. Sin esto, caeremos en lo que lamentaba Amaladoss: la falta de voces proféticas ante los ricos, que no sólo denuncien individuos, sino instituciones.

Hablando desde el primer mundo, y al primer mundo al cual pertenezco, conviene proclamar que esto no se hace sólo en interés de los pobres, sino también en interés nuestro. Ayer decía Teresa que África es un continente empobrecido por su misma riqueza, económicamente empobrecido por su riqueza natural, que la ha convertido en presa de todos los ambiciosos. El mundo rico es otro mundo 
empobrecido - humanamente-, por su misma riqueza elaborada. O con otro ejemplo, a mí me parece loable la propuesta del actual presidente del gobierno español de crear una "alianza de civilizaciones". Pero hemos de decir al señor Zapatero que una alianza de civilizaciones será imposible sin un NOEI, Nuevo Orden Económico Internacional. Ese nuevo orden fue decretado por Naciones Unidas hace ya más de treinta años, con una mayoría aplastante. Pero todos los países que votaron No o se abstuvieron eran, precisamente, los países más ricos - que luego presumimos de demócratas y pretendemos dar lecciones de democracia $^{4}$. Y el decreto de Naciones Unidas ha quedado totalmente inédito.

Y por si estas últimas reflexiones incitan al pesimismo, voy a concluir con dos citas fundamentales. La primera es lo que me dijo por teléfono una gran mujer nicaragüense, tras la corrupción del sandinismo: "Las personas fallan, fallamos, pero las causas siguen valiendo la pena".

La segunda es el estribillo de una canción litúrgica, que estuvo muy en boga hace años y hoy hemos olvidado. Sus diversas estrofas van describiendo situaciones: cuando un pobre nada tiene y aún reparte, cuando un hombre pasa sed y agua nos da, cuando el débil al hermano fortalece, cuando crece la alegría y nos inunda, cuando un hombre donde hay guerra pone paz, cuando amamos el sentir de los sencillos, cuando abunda el bien y llena los hogares... Y al acabar esa descripción, nunca decía que ya está arreglado el mundo, sino que repetía: "va Dios mismo en nuestro mismo caminar".

Creo que exactamente, es lo que yo he intentado decir y lo que resume mi impresión de estos días. Si todos lo viviéramos, habría sido innecesaria esta charla.

Postdata. Al poner por escrito estas notas para entregarlas a la imprenta, quiero añadir lo que me dijo una buena amiga sobre los textos de respuesta a las encuestas, que sirvieron de base para la reflexión teológica y que le he dado a leer: "estas páginas deberían ser libro de texto en todas las facultades y escuelas de teología". No sé si al incumplimiento de esa intuición se debe lo que hoy algunos califican — parodiando el viejo título de Marx - como "miseria de la teología".

4. España estaba entre los diez países que se abstuvieron, junto a Holanda, Italia, Japón, Noruega... Votaron en contra de la resolución: Estados Unidos, Gran Bretaña, Alemania, Bélgica, Dinamarca y Luxemburgo. ¡Qué bien si el nuevo secretario de Naciones Unidas recuperara ese decreto! 